\title{
Erratum to: Hopelessness, Temperament, Anger and Interpersonal Relationships in Holocaust (Shoah) Survivors' Grandchildren
}

\section{Paolo Iliceto • Gabriella Candilera • Diletta Funaro • Maurizio Pompili • Kalman J. Kaplan • Moriah Markus-Kaplan}

Published online: 2 December 2009

(C) Springer Science+Business Media, LLC 2009

\section{Erratum to: J Relig Health DOI 10.1007/s10943-009-9301-7}

In the above mentioned article, the last two paragraphs should be revised. They should read as follows:

A limitation of the present study is that the respondents were only 124 subjects equally divided among Holocaust survivor's grandchildren and grandchildren of a presumably nonJewish comparison group. Thus differences between the two groups may be a function both of having families that (1) underwent or did not undergo the horrendous Shoah experience, and (2) whether they were influenced or not influenced by the ancient and rich Jewish tradition, one which had a long experience of dealing constructively with traumatic events.

The online version of the original article can be found under doi:10.1007/s10943-009-9301-7.

P. Iliceto · M. Pompili

Department of Neurosciences and Mental Health, Suicide Prevention Center, Psychiatry Division, Sant'Andrea Hospital, Sapienza University of Rome, Rome, Italy

G. Candilera · D. Funaro

Clinical Psychologist, Private Practice, Rome, Italy

M. Pompili

McLean Hospital, Harvard Medical School, Boston, MA, USA

K. J. Kaplan

Department of Psychiatry, University of Illinois at Chicago College of Medicine, Chicago, IL, USA

M. Markus-Kaplan

Clinical Psychologist, Private Practice, Tel Aviv, Israel

M. Pompili $(\bowtie)$

Department of Psychiatry, Sant'Andrea Hospital, “Sapienza”' University of Rome,

1035 Via di Grottarossa, 00189 Rome, Italy

e-mail: maurizio.pompili@uniroma1.it; mpompili@mclean.harvard.edu 
Controlling for Jewishness would necessitate a comparison of grandchildren of Jewish survivors from a country occupied by the Nazis with a Jewish control group from a country not occupied by the Nazis (for example, the United States). Ideally, this part of the study would involve comparing Jewish groups in a country such as Italy, with a Jewish control group in The United States, and a Jewish group in Israel would yet be another important control. In addition non-Jewish control groups could be employed in these same three countries. Finally, future investigations would benefit from using larger samples, at least 100 subjects for each group, including Jewish and non-Jewish participants from these three countries. 